\title{
WIKI-BASED COLLABORATIVE LEARNING EXPERIENCE IN A FOREIGN LANGUAGE BLENDED COURSE
}

\author{
Tatiana Krasnova \\ (Tomsk Polytechnic University/Russia/krasnova@tpu.ru) \\ Tatiana Gorbatova \\ (Tomsk Polytechnic University/Russia/gtn@tpu.ru) \\ Alexandra Kudryashova \\ (Tomsk Polytechnic University/Russia/english@tpu.ru) \\ Anna Popova \\ (Tomsk Polytechnic University/Russia/anp13@tpu.ru)
}

\begin{abstract}
The article emphasizes the educational potential of wikis for learning foreign languages. It focuses on students' collaboration based on integration of different types of activities within a highly motivating blended learning environment where learners can interact and share their ideas. The study aims to understand if wikis could enhance online collaboration and positively affect students' attitudes to group work. It tries to explore the level of participation and contribution of students in wiki-based activities, as well as their attitude to this type of online collaboration.
\end{abstract}

Keywords: blended learning, computer-supported collaborative learning, digital native, wiki, Web 2.0.

\section{INTRODUCTION}

To respond to the many challenges higher education faces nowadays, educators should recognize new skills and abilities of modern students' generation who are often called digital natives. This term refers to those who have grown up during the widespread adoption of digital technologies. Computers and different gadgets are the integral part of their everyday life and have already become the extension of their body and mind. Researchers outline certain characteristics of digital natives. According to Teo et al, they:

- reach a series of new technologies;

- carry out multiple tasks and processes simultaneously;

- use technologies without any difficulty;

- use the Internet as the primary source for accessing the necessary information;

- reach the information quickly via more than one multimedia source;

- use the Internet for learning as in other activities [1].

Biggs also believes that the nature of student cohorts has changed quite considerably, with respect to diversity in ability, cultural background, learning preferences, technology experience, levels of motivation, and the time they are able or willing to spend on their study [2]. Some educational practitioners and researchers think that digital natives need to be taught in a completely different way [3,4]. Digital natives consider traditional modes of education boring and expect the use of technology in education as it has become an inevitable part of their lives.

In order to keep pace with the advancing technologies and meet the needs of the new generation of students, a paradigm shift is needed towards appropriate implementation of 
technology tools [5]. A convergence of new educational needs points to the necessity of integration of e-learning technologies into the educational process when teaching foreign languages. The crucial pedagogical problem is to understand how to incorporate these new technologies in order to enhance students' learning through deep engagement with the process of learning and the content of the course.

The main problem usually voiced by modern students is lack of motivation to study a foreign language due to perceived impracticableness of this process as defined by murky prospects of achieving any practical results [6]. Motivation was always seen as a driving force of learning, and now it is evident that digital natives will be more engaged with a digital learning tool than a traditional textbook.

Educators articulate various views on the rapidly expanding world of educational technologies but we want to focus on the promising potential of blended learning for enhancing learning experiences. Blended learning is of great interest now in teaching foreign languages. It is seen as an emerging and innovative educational approach because it changes students' behaviour and has a potential of transforming the whole learning process. Merging traditional classroom setting with its cooperative learning environment and web tools with their autonomous e-learning environment gives an opportunity to create a new unique blended learning environment that meets a variety of learning styles and improves students' engagement. Blended solution can give satisfactory outcomes, as it suggests a balanced proportion of online and traditional study. The emphasis is usually made not on the reduction of face-to-face sessions but on supplementing class contact time and providing greater opportunities for supporting a wide diversity of students' needs. Students' participation increases considerably as well as their interaction with the course content and collaboration with the peers. The goals of blended learning are to develop the foreign language competence for professional purposes, raise motivation, shape cognitive initiative and develop selforganization [7].

Technological advances drive new forms of blended learning activities and teaching practices. With the introduction of Web 2.0 digital natives ceased to only consume information from the Internet, they started also participating in the production of web content. Most Learning Management Systems (LMS) used in blended learning for creating the learning environment have incorporated Web 2.0 collaboration tools (chats, forums, blogs, wikis, etc.). The use of these familiar for digital natives tools in the educational settings could be very beneficial. The most popular form of social software in LMS is wiki. The role of the wiki can be defined as knowledge collaboration, contribution, storage, and sharing or exchange of information. In this study we tried to figure out if wikis could enhance online collaboration and positively affect students' attitudes to group work.

\section{THEORETICAL FRAMEWORK}

The increased connectivity of digital natives improves their collaboration abilities. Nowadays collaboration is seen as an important life skill and also it is a significant factor for academic achievement, student satisfaction and personal development. The opportunity to collaborate in a blended course can become a key element in preparation for future career. Ability to work in a team is considered as a main employment requirement. Thus collaboration shouldn't be underserved by higher education; on the contrary it should be integrated into authentic activities both during face-to-face meetings and in the online environment. Students learn how to exchange ideas and find innovative solutions performing group-based activities in order to create something new and reach a common goal. Recognizing themselves as part of the team, each student can make a contribution to joint decision-making because they 
understand that their common success depends on their individual efforts, initiative and selfsufficiency.

Not long ago collaboration was possible only in the classroom but now open source LMSs give an opportunity for academic community to easily integrate Web 2.0 collaboration tools in the learning environment. One of such vivid examples is Moodle which is often seen as the most accessible and effective tutorial; on the basis of this platform very engaging online tasks can be created. Moodle offers flexible and dynamic management of the learning process and satisfies new needs with regard to methodology and information technologies. Moodle makes it possible to create individualized process of learning where students can interact with each other and teachers, which encourages their close collaboration [8]. Students can study outside classes at any convenient time thereby increasing education efficacy.

Collaboration is the best feature of Moodle; Web 2.0 technologies integrated in this LMS facilitate self-directed, collaborative and responsible learning in educational settings [9]. The learning process with Web 2.0 tools becomes more social, personal and dynamic, it supports community building which is very typical for digital natives.

The most popular collaboration tool is wiki; it can be seen as an integral component of blended learning environment. Wikis represent new repositories of information and knowledge for personal and institutional purposes [10]. With the help of the wiki tool educators can create various collaborative writing activities, which provide speed of updating, ease of editing and collaboration, and overall simplicity. Wikis enhance the communication process by becoming the vehicle for sharing information, building on other students' knowledge base, and collaborating on new ideas [11].

How exactly do wikis work in Moodle? Every page in the wiki has a link at the top 'Edit', when you click it you can write your ideas in a box. Using the editing toolbar students can do some basic formatting of the text, add pictures and media. There is one more important feature of wiki, by clicking 'History' link you can track the changes that were made and see who made a contribution. History list makes it possible to revert to a previous version if somebody vandalized the wiki or erased something by mistake. The link 'Comments' can be used as a tool for discussions. Even files can be uploaded if needed. Fig.1 shows how a typical wiki in Moodle looks like.

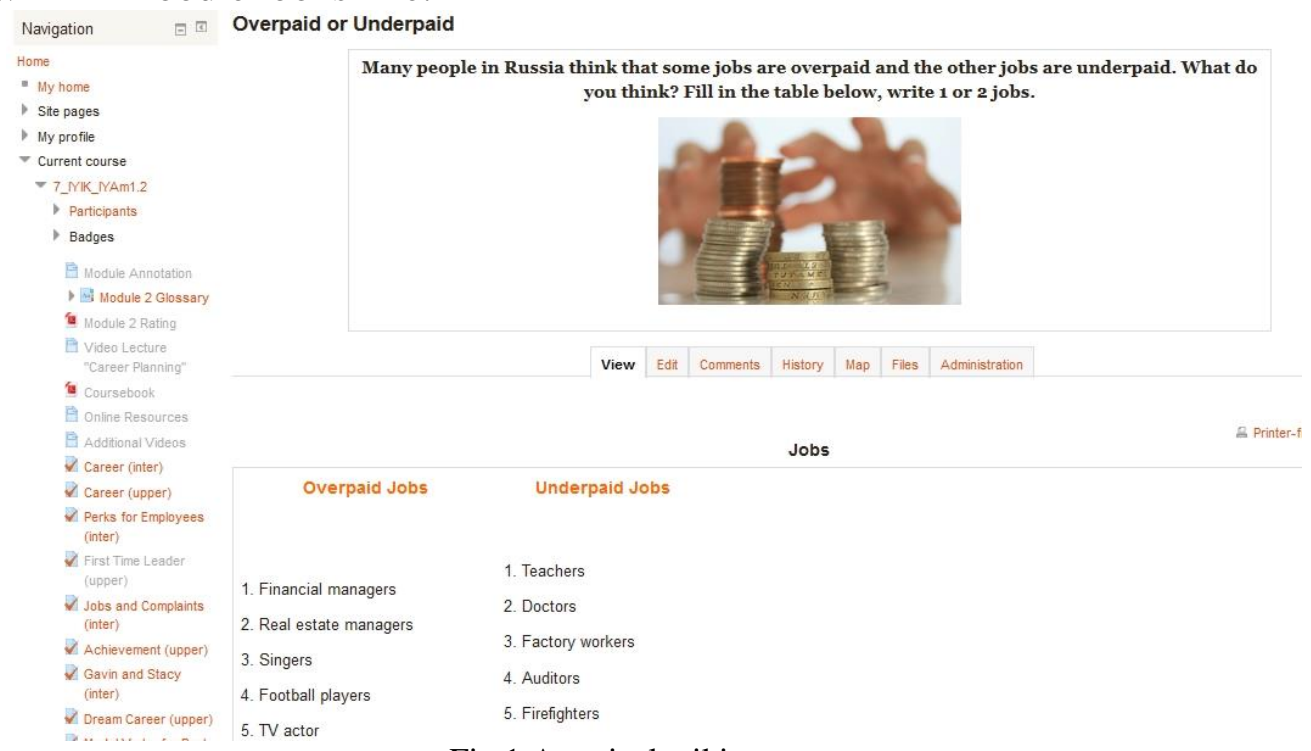

Fig.1 A typical wiki structure

Contributing to a wiki for the first time must be just as nerve wracking for students as the first forum contribution. Students may need some encouragement to get started, particularly if the 
tool is unfamiliar. They can be even shocked at the beginning that somebody can change their writing.

One of the best uses of wikis can be a library of resources both for students and educators. It could serve as a warehouse for different sources, links, media, instructions and other information necessary for the course. Everyone can contribute to this collection. Students can share interesting web sites, photos, videos; wikis can become a repository for class-made podcasts or instructions for assignments.

Another type of collaboration is a reciprocal wiki, which invites student participation in completing a task, making lists, collecting documentation, brainstorming and exchanging ideas [11]. Wikis can become a workshop for group projects or arrange collaborative writing activities. The main advantage of such wikis is that in wiki environments, learners participate in their own learning rather than passively receive it. They are actively engaged in the learning process and this can result in greater learning outcomes.

The third type of wikis can be called student-produced wikis. These wikis can be compared with easy web-sites created by students for sharing their reflections, ideas and opinions; students can create their own vocabulary lists, create polls for other students.

To sum up, the most prominent educational benefit of wikis is providing space for easy interaction and collaboration.

\section{METHODOLOGY}

This study is aimed to understand the level of participation and contribution of students in wiki-based activities, as well as their attitude to this type of online collaboration. The qualitative research approach was chosen for this study as we were willing to discover students' experiences and views of wiki-based collaborative learning in a foreign language blended course.

Tomsk Polytechnic University offers approximately 300 blended courses and the number is growing. Foreign language teachers take an active stand in the design of blended courses with personalized learning environments for their disciplines. The blended learning course presented in this paper was designed and offered as an obligatory course for first year students of Tomsk Polytechnic University, Institute of Cybernetics, who studied English as a second foreign language, their levels ranged from B1 to C1. The course entitled as "General English Blended Course" had face-to-face format and was supported with the online materials, discussions, wikis and other activities on Moodle platform.

A total of 48 undergraduate students (42 male and 6 female) were enrolled in this course. The majority was 18-19 years old and had good computer skills as they were going to specialize in Computer Science. They all had computers and laptops with Internet connection at home and in campus. We can assume that these students are digital natives who have certain amount of expertise and experience with new technologies. They meet three main criteria developed by Helsper and Eynon: age, experience, and breadth of use [12]. They have grown up with technology and don't know any other context, they are submerged in it for a long period of time, and the Internet is integrated into almost every aspect of their everyday lives.

The semester course consisted of 6 modules, each of which had a section called "Team work" with online discussions and wikis. Participants of the course worked together in group projects in forms of reciprocal wikis. Usually these were not time-consuming activities and they had very creative nature. We truly believe that the learning process should be founded as a creative process and give learners a possibility for personal expression in creative projects [13]. The asynchronous nature of wikis provided the flexibility for students so they could 
participate at any convenient time but the students had to stick to the deadlines for wiki submissions.

Throughout two semesters the authors took notes about the observations of students' online behaviour while they were working with wikis. But still the main source of study was qualitative interviews, which allowed participants to talk freely in their own words. A set of questions was used to understand how wiki-based activities were accepted by students and what their positive and negative aspects were.

\section{RESULTS}

Transmission of prior computer skills of digital natives in educational settings was very beneficial therefore there was no need of thorough instruction and students joined immediately in the work. As it was mentioned before each module of the course contained wikis, so this activity was quite frequent. With the help of online course statistics we can analyze students' participation level (Fig.2).

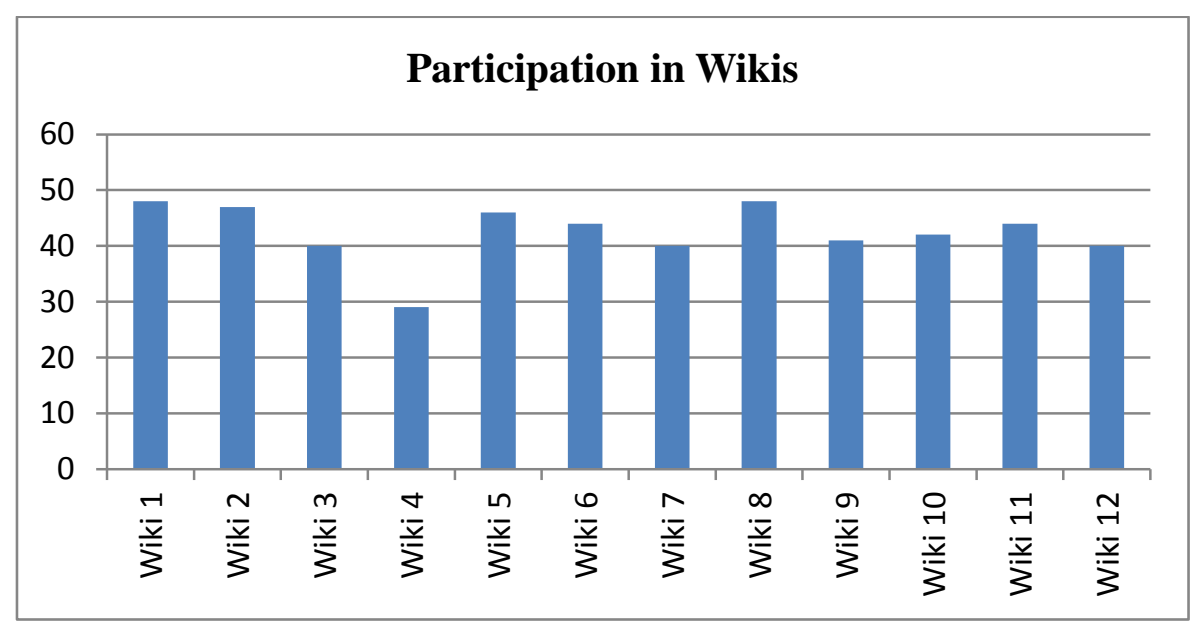

Fig. 2 Students' participation in wikis

The graph shows that overall level of participation is very high; we can assume that students were engaged with this type of activity. The maximum participation was noticed in Wiki 1 and Wiki 8; all 48 group members took part in them. High level of participation in the first wiki where students had to compare healthy and unhealthy lifestyles and describe the effects each lifestyle had on person's health could be explained by curiosity to a new type activity. Participants reported that they had never done anything like this before and were extremely intrigued by using wiki in the educational context. Wiki 8 was called the most successful and absorbing. It was designed to promote collaborative story writing. According to the task of the wiki the students should write a story together (Fig.3). 


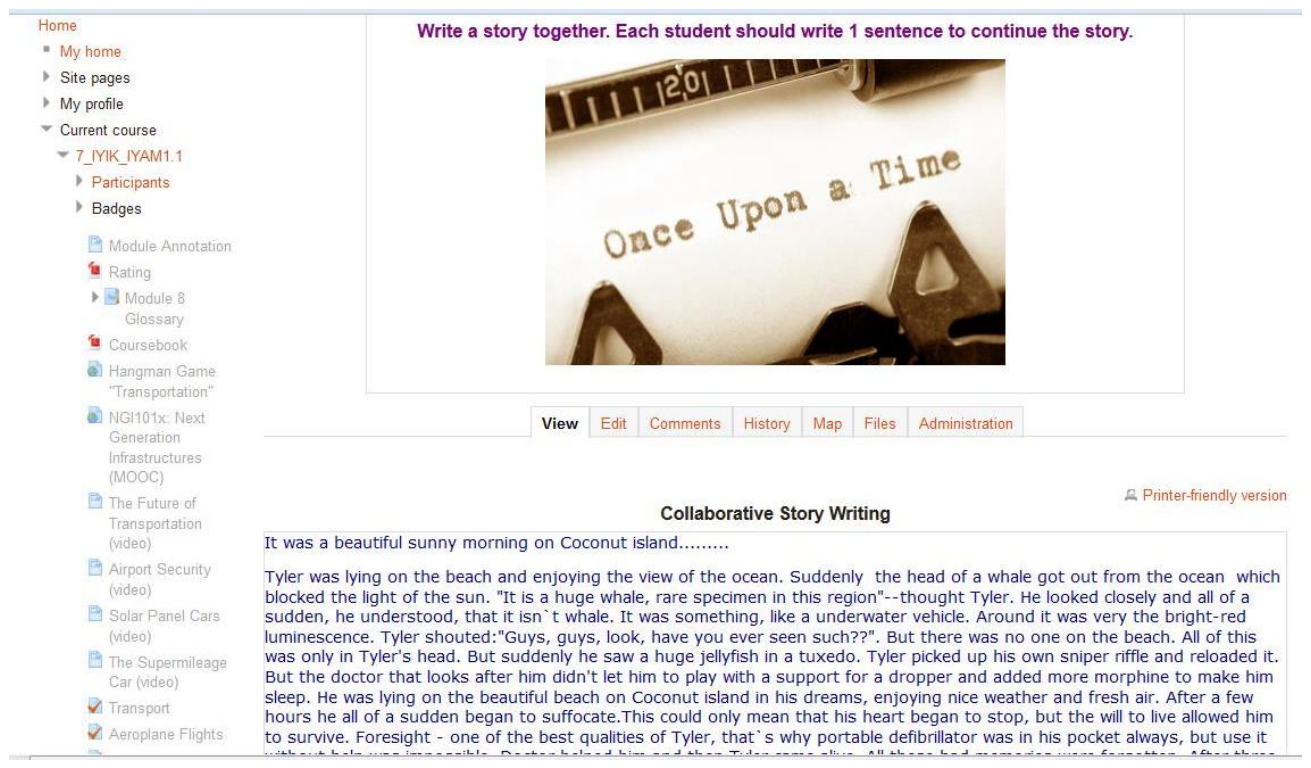

Fig. 3 Collaborative story writing wiki

They had only one sentence generated by the tutor with which the story began. Each student had to write only one sentence but in fact some of them wrote more and even returned several times to give new contributions to the story. The story had lots of plot twists and students read this wiki on a regular basis to keep track of the story. They often addressed the "History" button to see who killed the main character again. When the wiki closed students wanted to know the end of the story and asked the tutor to open it. This task was very motivating and gave hilarious results.

Returning to the participation graph we should analyze an unexpected drop in Wiki 4, where only 29 students took part. The wiki was called "Peer correction activity" in which students had to choose any peer's piece of writing from a discussion forum, then find and analyze grammar and spelling mistakes. Students reported that after performing a series of creative and engaging wikis they were a bit disappointed with such a serious task demanding a lot of efforts. Others said that it was hard for them to assess their peers because they didn't want to hurt them and it was very hard to be objective. Probably this task wasn't suitable for wiki format as it should be done anonymously.

The problem of lurkers in wikis is mainly typical for all online activities. Students didn't participate in some wikis because of procrastination problem, when they put off the task till the deadline and lagged behind the peers. The other reason of non-participating is lack of ideas or somebody wrote the idea they wanted to suggest.

The level of interaction and contribution was different in each wiki but it was mainly grounded by the task itself. In most cases these were just 'mini-wiki tasks' aiming to complete a table or chart. In these wikis collaboration was very low; wikis were used mainly for data collection which then was used for live discussions in the classroom. But other wikis were capable of showing high level of interaction, for example Wiki 5 contained a problem-solving activity aiming to pack a suitcase in a certain emergency situation described in the task. Performing this wiki, students had a lot of fun; this becomes obvious from the entries they had. A typical suitcase contained money, documents, food, clothes and a telephone, but some very imaginative students took fake documents, father's gun, a dynamite belt, a bulletproof vest, a wig, a little teddy bear, a make-up bag, a first aid kit and even an epic black hat. 
Having seen these extraordinary ideas, students started commenting on these entries and writing questions to the peers asking for explanations.

Another example of intensive collaboration was Wiki 11, which was chosen as a virtual space for euthanasia debate preparation. Affirmative and negative teams used wiki for collecting pro and against arguments, quotations and other important information. The teams could see the opposing arguments in order to build their strategy for the rebuttal stage. Students found wiki format very useful and convenient for this task.

\section{DISCUSSION}

The students all had different language level but nearly the same experience of technology. Being tech savvies they were enthusiastic about blended learning approach, students quickly adapted to new conditions and didn't feel uncomfortable with new teaching techniques. The interviews revealed that students saw the online course as "a virtual space for creative learning".

One key positive aspect from this study was that the majority of students called wiki tool their favourite collaboration tool alongside with discussion forums. They were active participants of wiki-based activities and tried to contribute to the common group goal. Students in this study indicated that they were more excited about wikis than tests and assignments; they believed that wikis created a more enjoyable learning experience and made them more motivated. Some students demonstrated genuine group collaboration and operated at higher cognitive levels.

Talking about positive and negative aspects, students appreciated the idea of editing one common document and sharing their ideas with the peers. But they insisted on creative tasks for wikis eliminating grammar and vocabulary based activities, reporting that they had enough online tests and assignments. Thus, we may assume that the success of wikis is strongly dependent on the proper wiki design.

The participants outlined the increase of responsibility while participating in wikis; they tried to be very careful about the editing process to minimize the risks of erasing someone's idea or writing something offensive or inappropriate. Imposing certain amount of freedom on students helped develop learner autonomy that allowed acquiring new knowledge and developing new skills [8]. A key finding for this study is that wikis showed great potential for transforming teacher-centered education to learner-centered one. When students share and discuss something they experience truly learner-centered moments, they become individuals who construct their own knowledge and are able to contribute it to the learning community.

The main attraction of wikis was that performing wiki-based tasks they demonstrated critical thinking skills through ideas exchanging, analysis and synthesis. Online environment that supported students' interaction facilitated active learning and increased learners' involvement with the subject content.

The overall results of using wikis in the online course were encouraging; most students saw wikis as a valuable collaborative tool and highly appreciated the chance of exchanging ideas with the peers.

\section{CONCLUSIONS}

With the help of Web 2.0 technologies integrated into Moodle the learning space was considerably expanded providing multiple opportunities for students' engagement, communication, content and resource sharing [14]. Wiki-based collaboration was challenging but quite successful, it became a great motivator for students and developed their potential for learning. The use of this blended learning tool required a range of skills; students learnt how 
to work as a team and how to create a community, they had to collaborate effectively together to accomplish their goals. As a result, we believe that students' learning was enhanced through wiki-based collaboration. Further research is needed to show the benefits of wikibased collaboration to learning outcomes.

\section{REFERENCES}

1. Teo, T., Kabakçı Yurdakul, I., \& Ursavaş, Ö. F. (2014). Exploring the digital natives among pre-service teachers in Turkey: a cross-cultural validation of the Digital Native Assessment Scale. Interactive Learning Environments, 1-14.

2. Biggs, J. B. (2011). Teaching for quality learning at university: What the student does. McGraw-Hill Education (UK).

3. Prensky, M. R. (2012). From digital natives to digital wisdom: Hopeful essays for 21st century learning. Corwin Press.

4. Rosen, L. D. (2010). Rewired: Understanding the iGeneration and the way they learn. Macmillan.

5. Krasnova, T., \& Vanushin, I. (2016). Blended Learning Perception among Undergraduate Engineering Students. International Journal of Emerging Technologies in Learning (iJET), 11(01), 54-56. DOI: http://dx.doi.org/10.3991/ijet.v11i01.4901

6. Aksenova, N. V., Shepetovsky, D. V., Mironova, V. E., Stepura, S. N., \& Pichugova, I. L. (2015). Developing Student's Motivation to Learn Foreign Language in Tertiary Classroom and Beyond. Mediterranean Journal of Social Sciences, $6(5), \quad 240 . \quad$ DOI: http://dx.doi.org/10.5901/mjss.2015.v6n5s1p240

7. Kudryashova, A. V., Gorbatova, T. N., \& Rozhkova, N. E. (2016). Developing a blended learning based model for teaching foreign languages in engineering institutions. SHS Web of Conferences, Vol. 28, p. 01128. EDP Sciences. DOI: http://dx.doi.org/10.1051/shsconf/20162801128

8. Krasnova, T., \& Demeshko, M. (2015). Tutor-mediated Support in Blended Learning. Procedia-Social and Behavioral Sciences, 166, 404-408. DOI: http://dx.doi.org/10.1016/j.sbspro.2014.12.544

9. Rollett, H., Lux M., Strohmaier M., Dösinger G. \& Tochtermann K. (2007). The Web 2.0 Way of Learning with Technologies. International Journal of Learning Technology, Vol. 3, No. 1, pp. 87 - 107

10. Pontes, E., Silva, A., Guelfi, A., \& Kofuji, S. T. (2012). Methodologies, Tools and New Developments for E-Learning. InTech. 41 Madison Avenue 31st Floor, New York, NY 10010.

11. Teehan, K. (2010). Wikis: The Educator's Power Tool. ABC-CLIO.

12. Helsper, E. J., \& Eynon, R. (2010). Digital natives: where is the evidence? British educational research journal, 36(3), 503-520.

13. Didenko, A. V., Aksenova, N., \& Loginova, A. V. (2016). The Choice of Effective Methods and Approaches to the Design of an Online Course. International Journal of Emerging Technologies in Learning (iJET), 11(04), 150-152. DOI: http://dx.doi.org/10.3991/ijet.v11i04.5270

14. Roussinos, D., \& Jimoyiannis, A. (2013) Analysis of students' participation patterns and learning presence in a wiki-based project, Educational Media International, 50:4, 306-324, DOI: http://dx.doi.org/10.1080/09523987.2013.863471 